\title{
Complexation of Dicarboxylic Acids Containing Ferrocene Nucleus with Aluminium Ion ${ }^{\dagger}$
}

\author{
Yutaka OKADA* and Yoshihiro NAKAJIMA \\ Department of Applied Chemistry, Faculty of Science and Engineering, Ritsumeikan University \\ (1-1-1 Nojihigashi, Kusatsu-shi 525-8577, JAPAN)
}

Edited by J. Sekiya, Kyoto Univ., and accepted August 19, 2005 (received for review February 28, 2005)

\begin{abstract}
IR and ${ }^{27} \mathrm{Al}$ NMR spectra of 1,1'-bis( $\omega$-carboxyalkanoyl)ferrocenes in the presence of metal ions indicated complexation of 1,1'-bis(3-carboxypropanoyl)ferrocene and 1,1'-bis(5-carboxypentanoyl)ferrocene with aluminium ion.
\end{abstract}

Key words: ${ }^{27} \mathrm{Al}$ NMR, IR, Metal-complexation, ferrocene derivative

\section{Introduction}

One of the interesting features of ferrocene derivatives is the rotation of the cyclopentadienyl $(\mathrm{Cp})$ rings. For the unsubstituted ferrocene, its two $\mathrm{Cp}$ rings in the molecule freely rotate around the $\mathrm{Cp}-\mathrm{Fe}-\mathrm{Cp}$ bond axis in the solution (1). The ferrocene nucleus with substituents $\mathrm{A}$ and $\mathrm{B}$ on the different $\mathrm{Cp}$ rings would be found as an axis bonding $\mathrm{A}$ and $\mathrm{B}$.

In a previous study (2), the authors carried out hydrolysis of $1,1^{\prime}$ '-bis [ $\omega$-(methoxycarbonyl)alkanoyl] ferrocenes. The relationship between the reactivity and specific structure was then discussed. As a result, for the compounds which have the same 1- and 1'-substituents, the $\mathrm{k}_{1}$ and $\mathrm{k}_{2}$ values are different. This may be caused by the electrostatic interaction between the two carbonyl groups.

In this study, the interaction between the carboxyl groups and metal ions, and the conformation of the ferrocene nucleus were discussed from the spectral data of the carboxylic acids prepared from 1,1 '-bis $[\omega$ (methoxycarbonyl)alkanoyl]ferrocenes by hydrolysis.

\section{Experimental}

The 1,1'-bis(3-carboxypropanoyl) ferrocene (1), 1,1'-bis(5-carboxypentanoyl)ferrocene (2) and 1,1'bis(9-carboxynonanoyl)ferrocene (3) were prepared by known methods (3). The compounds were identified by ${ }^{1} \mathrm{H}$ NMR, IR, and mass spectra as described in the previous paper (2).

The IR spectra were measured with a Shimadzu FTIR 8400 spectrometer by use of nujol mull method. ${ }^{27} \mathrm{Al}$ NMR spectra were recorded with a JEOL A-400 spectrometer operating at $104 \mathrm{MHz}$. The pulse width was $20 \mu \mathrm{s}$, and the scan time was 400 . The measurements were carried out for a $5 \%(\mathrm{w} / \mathrm{w})$ methanol- $\mathrm{d}_{4}$ solution at ambient temperature using $5 \mathrm{~mm} \phi$ sample tubes. The chemical shifts were referenced to $\mathrm{AlCl}_{3}$ as the external reference.

\section{Results and Discussion}

The IR spectra of compounds 1-3 in addition to benzoic acid and phthalic acid were measured in the presence of metal ions. The carbonyl stretching wavenumbers of the carboxyl groups are shown in Table 1. In

\footnotetext{
${ }^{*}$ Correspondence to: Yutaka OKADA, Faculty of Science and Engineering, Ritsumeikan University, 1-1-1 Nojihigashi, Kusatsu-shi 525-8577, JAPAN

E-mail: ygvictor@se.ritsumei.ac.jp

${ }^{\dagger}$ Studies on Ferrocene Derivatives. Part XVII
} 
this table, the differences in the wavenumbers in the absence and presence of the metal ions are also shown. $\mathrm{Na}^{+}$did not make a shift. For benzoic acid, no differences were observed when the ions were added. These ions would not coordinate to this acid. However, for phthalic acid, small shifts were observed when the ions except $\mathrm{Na}^{+}$were added (Table 1). This would be caused by the decrease in the double bond character of the carbonyl groups due to the coordination of these ions to the carbonyl oxygens (4). The order of the magnitudes of the shifts by the alkaline-earth metal ions was $\mathrm{Mg}^{2+}>\mathrm{Ca}^{2+}>\mathrm{Ba}^{2+}$. Namely, this order shows the coordination facility to the carbonyl oxygens. This order is similar to that of the complex-forming ability of the alkaline-earth metal ions (5).

The IR spectra of the ferrocene derivatives $\mathbf{1}$ and $\mathbf{2}$ in the presence of the alkaline-earth metal ions or aluminium ion showed the lower shifts in the wavenumber for the phthalic acid. Namely, an interaction between these ferrocene derivatives and the ions is suggested. In contrast, for the ferrocene derivative $\mathbf{3}$, which has longer methylene chains, the shift was not observed in the presence of ions. As mentioned in the previous paper (2), for the conformations in which the 1- and 1'-substituents are adjacent, the two terminal carbonyl groups are able to approach with more difficulty than for the lower member compounds $\mathbf{1}$ and $\mathbf{2}$. As a result, the interaction mentioned above would not occur in compound $\mathbf{3}$. From the results that only compounds $\mathbf{1}$ and $\mathbf{2}$ form complexes, these compounds act as bidentate ligands in which the two carbonyl groups are coordination points.

The ${ }^{27} \mathrm{Al}-\mathrm{NMR}$ spectra were measured in order to examine the coordination of the aluminium ion to the ferrocene derivatives. The spectra of $\mathrm{AlCl}_{3}$ in the presence of derivatives $\mathbf{1}$ and $\mathbf{3}$ are shown in Fig. 1. The chemical shifts of the ${ }^{27} \mathrm{Al}$ NMR spectra are summarized in Table 2. The chemical shift of $\mathrm{AlCl}_{3}$ was defined as 0 . When $\mathrm{AlCl}_{3}$ was added to phthalic acid at the equimolar ratio, a new higher field peak appeared at $-6.4 \mathrm{ppm}$ (6). The new peak became relatively larger at the molar ratio of $5\left(\mathrm{AlCl}_{3} /\right.$ substrate $)$. It seems that the lower field peak is due to $\mathrm{AlCl}_{3}$ and the higher one is due to the complex between the phthalic acid and $\mathrm{AlCl}_{3}$. The ${ }^{27} \mathrm{Al}$ chemical shifts are governed by a diamagnetic term; the observed higher field shifts should be caused by the interaction between the $\mathrm{Al}$ atom and carbonyl oxygen having an electron donating facility (7).

For the ferrocenes, when $\mathrm{AlCl}_{3}$ and compound 1 were mixed, a higher field peak was observed at -6.7 ppm (Fig. 1). This peak would be due to the complex between $\mathrm{AlCl}_{3}$ and compound $\mathbf{1}$ as found in the phthalic acid complex. This result supported the fact that derivative 1 forms a complex with $\mathrm{Al}^{3+}$ based on the IR measurement. For compound $\mathbf{3}$, only one major peak due to $\mathrm{AlCl}_{3}$ appeared, while a higher field peak was very weak (Fig. 1). Namely, compound 3, which has longer methylene chains, would not or little form a complex with $\mathrm{AlCl}_{3}$.

In summary, based on the IR and ${ }^{27} \mathrm{Al}$ NMR spectra, 1,1'-bis(3-carboxypropanoyl)ferrocene (1) and 1,1'bis(5-carboxypentanoyl)ferrocene (2), which have shorter methylene chains, act as bidentate ligands to form complexes with the metal ions. This result means that the two $\mathrm{Cp}$ rings of these ferrocene derivatives are restricted to rotate around the $\mathrm{Cp}-\mathrm{Fe}-\mathrm{Cp}$ bond axis by forming complexes with these metal ions. However, the

Table 1 IR Stretching Wavenumbers of Carboxy Groups.

\begin{tabular}{lccccccc}
\hline & \multicolumn{7}{c}{ Wavenumber $\left(\mathrm{cm}^{-1}\right)$} \\
\cline { 2 - 8 } Compounds & none & $\mathrm{Mg}^{\mathrm{a}}$ & $\mathrm{Ca}^{\mathrm{a}}$ & $\mathrm{Ba}^{\mathrm{a}}$ & $\mathrm{Al}^{\mathrm{a}}$ & $\mathrm{Na}^{\mathrm{a}}$ \\
\hline Benzoic acid & 1670 & --- & --- & -- & $1669(-1)^{\mathrm{b}}$ & $1669(-1)^{\mathrm{b}}$ \\
Phthalic acid & 1672 & $1635(-37)^{\mathrm{b}}$ & $1647(-25)^{\mathrm{b}}$ & $1654(-18)^{\mathrm{b}}$ & $1650(-22)^{\mathrm{b}}$ & $1672(0)^{\mathrm{b}}$ \\
Compound $\mathbf{1}$ & 1673 & $1662(-11)^{\mathrm{b}}$ & $1656(-17)^{\mathrm{b}}$ & $1662(-11)^{\mathrm{b}}$ & $1663(-10)^{\mathrm{b}}$ & $1673(0)^{\mathrm{b}}$ \\
Compound $\mathbf{2}$ & 1667 & $1657(-10)^{\mathrm{b}}$ & $1657(-10)^{\mathrm{b}}$ & $1660(-7)^{\mathrm{b}}$ & $1658(-9)^{\mathrm{b}}$ & $1667(0)^{\mathrm{b}}$ \\
Compound 3 & 1678 & $1678(0)^{\mathrm{b}}$ & $1678(0)^{\mathrm{b}}$ & $1678(0)^{\mathrm{b}}$ & $1678(0)^{\mathrm{b}}$ & $1678(0)^{\mathrm{b}}$ \\
\hline a & $\begin{array}{l}\text { The sample were yielded by mixing of the acids and the corresponding hydroxides in methanol } \\
\text { followed by evaporation of the solvent. }\end{array}$ \\
b The shifts in the wavenumbers in the absence and presence of the metal ions.
\end{tabular}




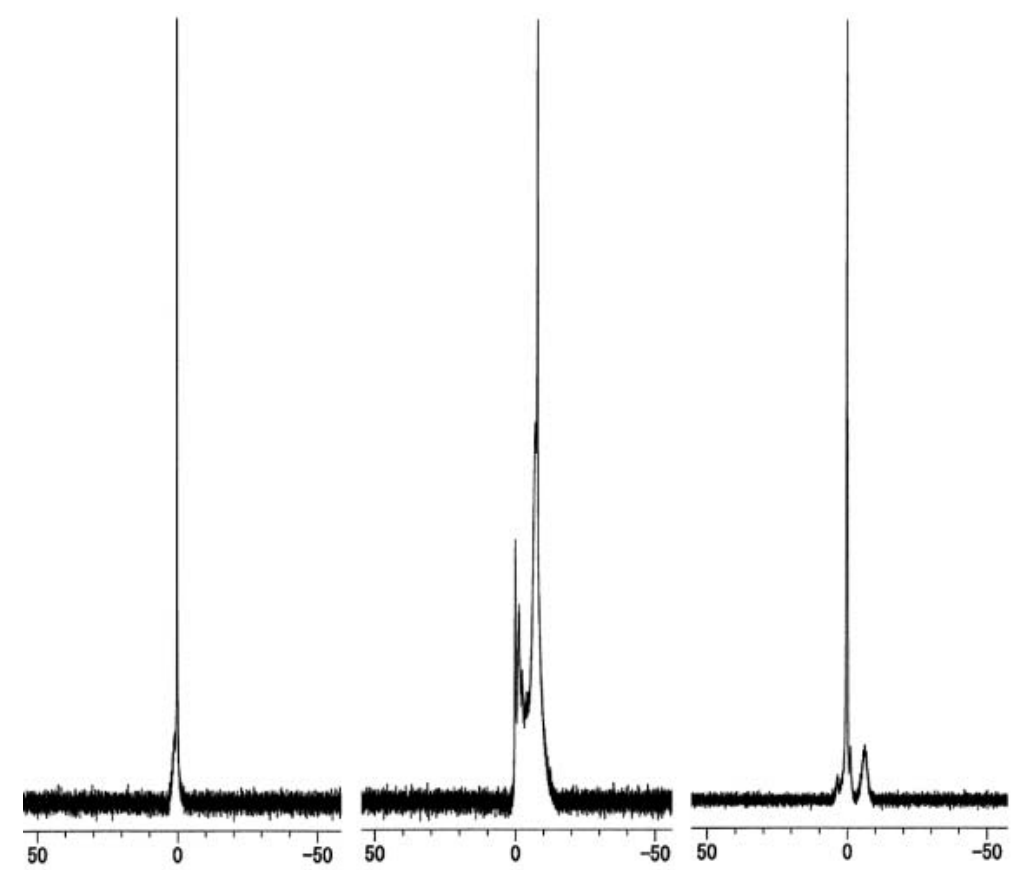

Fig. $1{ }^{27} \mathrm{Al}$-NMR $\mathrm{AlCl}_{3}$ Alone (left), in the Presence of Compound 1 (middle) and Compound $\mathbf{3}$ (right).

Table $2{ }^{27} \mathrm{Al}$-NMR Chemical Shifts of $\mathrm{AlCl}_{3}$ in the Presence of Carboxylic Acids.

\begin{tabular}{lccc}
\hline \multicolumn{1}{c}{ Samples } & Ratio & \multicolumn{2}{c}{ Chemical shifts (ppm) } \\
\hline $\mathrm{AlCl}_{3}$ & & 0 & \\
$\mathrm{AlCl}_{3} /$ Benzoic acid & $1: 1$ & 0 & \\
$\mathrm{AlCl}_{3} /$ Phthalic acid & $1: 1$ & 0 & -6.4 \\
$\mathrm{AlCl}_{3} /$ Phthalic acid & $5: 1$ & 0 & -6.4 \\
$\mathrm{AlCl}_{3} /$ Compound 1 & $1: 1$ & 0 & -6.7 \\
$\mathrm{AlCl}_{3} /$ Compound 3 & $1: 1$ & 0 & \\
\hline
\end{tabular}

metal ions would not coordinate to the 1,1'-bis(9-carboxynonanoyl)ferrocene (3).

\section{References}

1. H.H. RICHMOND and H. FREISER, The Electric Moments of Mono- and Diacetyl-ferrocene, J. Am. Chem. Soc., Vol. 77, 2022-2023 (1955).

2. Y. OKADA, H. KUNITOMO, S. IKARIYA and T. HAYASHI, Studies on Ferrocene Derivatives. XV. Hydrolysis of Diesters Containing a Ferrocene Nucleus, Synth. React. Inorg., Met. Org., Chem., Vol. 32, 1649-1660 (2002).

3. K.L. RINEHART Jr., R.J. CURBY Jr. and P.E. SOKOL, Organic Chemistry of Ferrocene. II. The Preparation of $\omega$-Ferrocenyl Aliphatic Acids, J. Am. Chem. Soc., Vol. 79, 3420-3424 (1957).
4. J.L. WUEPPER and A.I. POPOV, Spectroscopic Studies of Alkali Metal Ions and Ammonium Ions in 2-Pyrrolidones, $J$. Am. Chem. Soc., Vol. 91, 4352-4356 (1969).

5. C.A. CHANG, Selectivity of Macrocyclic Aminocarboxylates for Alkaline-earth Metal Ions and Stability of Their Complexes, J. Chem. Soc., Dalton Trans., 2437-2450 (1996).

6. T. YOKOYAMA, H. ABE, T. KURISAKI and H. WAKITA, ${ }^{13} \mathrm{C}$ and ${ }^{27}$ Al NMR Study on the Interaction in Acidic Aqueous Solution between Aluminium Ion and Trion, Salicyclic Acid and Phthalic Acid: as Model Compounds with Functional Groups of Fulvic Acid, Anal. Sci., Supplement, Vol. 13, 425-428 (1997).

7. T. YOKOYAMA, H. ABE, T. KURISAKI and H. WAKITA, ${ }^{13} \mathrm{C}$ and ${ }^{27} \mathrm{~A} 1$ NMR Syudy on the Interaction between Aluminium Ion and Iminodiacetic Acid in Aidic Aqueous Solutions, Anal. Sci., Vol. 15, 393-395 (1999). 